\title{
Integrating supplier knowledge in new product development projects: decoupled and coupled approaches
}

\author{
David T. Rosell, Nicolette Lakemond and Lisa Melander
}

\begin{abstract}
Purpose - The purpose of this paper is to explore and characterize knowledge integration approaches for integrating external knowledge of suppliers into new product development projects.

Design/methodology/approach - This paper is based on a multiple, in-depth case study of six product development projects at three knowledge-intensive manufacturing firms.

Findings - Firms make purposeful choices to devise knowledge integration approaches when working in collaborative buyer - supplier projects. The knowledge characteristics of the supplier input guide the choice of either coupling knowledge sharing and combining across firms or decoupling knowledge sharing (across firms) and knowledge combining (within firms).

Research limitations/implications - This study relies on a limited number of case studies and considers only one supplier relationship in each project. Further studies could examine the challenge of knowledge integration in buyer - supplier relationships in different contexts, i.e. in relation to innovation complexity and uncertainty.

Practical implications - Managers need to make choices when designing knowledge integration approaches in collaborative product development projects. The use of coupled and decoupled approaches can help balance requirements in terms of joint problem-solving across firms, the efficiency of knowledge integration and the risks of knowledge leakage.

Originality/value - The conceptualization of knowledge integration as knowledge sharing and knowledge combining extends existing perspectives on knowledge integration as either a transfer of knowledge or as revealing the presence of pertinent knowledge without entirely transmitting it. The findings point to the complexity of knowledge integration as a process influenced by knowledge characteristics, perspectives on knowledge, openness of firm boundaries and elements of knowledge sharing and combining.
\end{abstract}

Keywords New product development, Knowledge sharing, Suppliers, Knowledge integration, Knowledge combining

Paper type Research paper

\section{Introduction}

Knowledge has been identified as a critical resource for the innovativeness, competitiveness and survival of the firm (Grant, 1996). New product development (NPD) in particular has been characterized as a knowledge-based activity, and new products have been described as "the fruit of the fusion of new and existing knowledge" (lansiti, 1995, p. 521). It has long been acknowledged that knowledge is normally widely dispersed (Hayek, 1945), but more recently, the importance of using external knowledge in firms' innovation processes has been increasingly highlighted in research and practice in innovation management. The positive effects of using external knowledge in relation to innovation performance have been confirmed in several fields of study, such as research and development (R\&D) alliances (de Man and Duysters, 2005), buyer - supplier collaborations (Lau et al., 2010) and networks (Mu and Di Benedetto, 2012). Moreover, the
David T. Rosell is based at the Department of Management and Engineering, Linköping University, Linköping, Sweden. Nicolette Lakemond is Professor at the Department of Management and Engineering, Linköping, Sweden. Lisa Melander is based at Chalmers University, Gothenburg, Sweden.
(C) David T. Rosell, Nicolette Lakemond and Lisa Melander Published by Emerald Publishing Limited. This article is published under the Creative Commons Attribution (CC BY 4.0) licence. Anyone may reproduce, distribute, translate and create derivative works of this article (for both commercial and non-commercial purposes) subject to full attribution to the original publication and authors.

The full terms of this licence may be seen at http:// creativecommons.org/licences/ by/4.0/legalcode

Received 10 October 2016 Revised 26 March 2017 Accepted 23 April 2017 
prospective benefits of external knowledge are emphasized in particular in literature on open innovation (Chesbrough, 2003; Dahlander and Gann, 2010) and confirmed in empirical studies (Laursen and Salter, 2006; Remneland-Wikhamn and Knights, 2012). Open innovation suggests that NPD processes need to become more open in a way that allows knowledge to cross firm boundaries. However, there are limits to the benefits of openness; Laursen and Salter (2006) show a curvilinear relationship between openness and innovation performance, showing that too much openness results in a decrease in performance. This clearly signals that there are costs involved in the transactions across firm boundaries that involve knowledge (Knudsen and Mortensen, 2011). These costs depend upon the mode of integration used (Grant and Baden-Fuller, 2004; Grant, 1996). While knowledge integration in terms of influencing factors and knowledge integration outcomes has been examined intensely, there is a lack of in-depth analysis and poor understanding of underlying processes and mechanisms of knowledge integration in general (Tell, 2011; Kraaijenbrink, 2012; Foos et al., 2006) and specifically in the context of buyer - supplier collaboration in NPD. More detailed insight into these processes is crucial to formulate successful NPD practices when relying on external knowledge. Accordingly, this paper explores and characterizes knowledge integration approaches and mechanisms that are used to integrate external knowledge of suppliers into NPD projects.

Based on a multiple, in-depth case study of six product development projects at three knowledge-intensive manufacturing firms, this paper provides new and detailed insights into knowledge integration in NPD collaborations by describing how the knowledge characteristics both of the supplier's contribution and in relation to the context drive the use of knowledge integration approaches. The remainder of the paper is structured into four sections. First, a short theoretical framework determines the importance of and conceptualizes knowledge integration in collaborative NPD projects involving suppliers. Next, methodological choices are discussed, including the selection of the cases, data collection and analysis. This is followed by a detailed description of knowledge integration in six buyer - supplier collaborations. The cross-case analysis reveals patterns of knowledge integration mechanisms in relation to the knowledge characteristics of the supplier's input and the context. This results in the characterization of two knowledge integration approaches for integrating supplier knowledge into NPD projects. The article concludes with suggestions for future research.

\section{Theoretical framework}

\section{Knowledge integration}

When knowledge is a primary source of value (Grant, 1996), and it is not likely that all necessary knowledge resides in a single firm (Grant and Baden-Fuller, 2004; Kogut and Zander, 1992), the integration of firm internal and external knowledge is essential to achieve competitive advantage (Lawson et al., 2009). Knowledge integration can be defined as "combining specialized but complementary knowledge" (Tell, 2011, p. 27), which is particularly important in organizational contexts. It denotes that organizations are composed of members with specialized knowledge who will not automatically work together. Rather, substantial communication and coordination efforts are necessary to coordinate a cohesive organizational knowledge base (Kraaijenbrink, 2012). These efforts reflect the process of knowledge integration, which is particularly important in knowledge-intensive processes such as those in product development (Prieto et al., 2009; Carlile, 2002, 2004). Previous research has examined and discussed two distinct approaches to knowledge integration. First, knowledge integration has been described as a process of transferring knowledge to learn from each other and overcome difficulties in communicating and collaborating (Brown and Eisenhardt, 1995). Knowledge transfer builds on the transmission of knowledge from one individual or organization to another. This knowledge transfer perspective has gained wide acceptance in literature on buyer - 
supplier relationships (Kotabe et al., 2003; Modi and Mabert, 2007; Lawson et al., 2009; Cousins et al., 2011; Wagner, 2003). However, transfer-driven knowledge integration is inherently time-consuming, inefficient and difficult (Grant, 1996). Therefore, a second approach to knowledge integration has been described as a synthesis of disparate specialized knowledge without the entire transfer of that knowledge (Alavi and Tiwana, 2002). This second approach involves revealing the presence of pertinent knowledge without necessarily transmitting it entirely (Tiwana and McLean, 2005). Although existing literature on buyer - supplier relationships primarily seems to be based on perspectives of knowledge integration through knowledge transfer, i.e. which could be measured in terms of the technical, market, product or process knowledge that is gained through the transfer (Parker, 2012), knowledge transfer is often operationalized based on measures related to close relationships, bilateral communication, frequent contact, informal discussions and early involvement (Lawson et al., 2009; Cousins et al., 2011; Kotabe et al., 2003). These measures reflect important mechanisms and point to the importance of interpersonal interaction but do not actually describe whether knowledge integration is achieved through transfer of knowledge based on a synthesis of knowledge held by the individuals involved. In other words, previous research fails to provide insight into whether knowledge is considered as a resource or knowledge as knowing (Okhuysen and Eisenhardt, 2002). This distinction is important, as it is related to how knowledge integration processes are managed (Kumar and Ganesh, 2011). Dixon (2000) argues that the type of process depends on contextual characteristics, i.e. is related to the similarity of the task and context of the actors involved in the knowledge integration process, the nature of the task in terms of how routine and frequent it is and the type of knowledge (tacit or explicit) that is being integrated. In relation to non-routine tasks, such as are often performed in product development projects, Dixon makes a distinction between three different types of knowledge transfer that also could be applied to knowledge integration processes. First, far knowledge integration involves the integration of tacit knowledge. Far transfer makes it possible to leverage individuals' specialized and critical knowledge but requires that the knowledge is customized to the specific situation. This requires translation and contextualization (Galunic and Rodan, 1998) and thus a certain degree of interpretation. Second, strategic knowledge integration involves very complex knowledge that affects large parts of a system. A process of knowledge integration in the context of strategic transfer relies to a large extent on the interpretation of knowledge in real-time with the actors involved. Without interpretation and synthesis, it is unlikely that these actors can arrive at new understandings of the knowledge, limiting the number of potential recombinations (Marsh and Stock, 2006). Third, expert transfer concerns explicit knowledge that can be offered without much interpretation to address an unusual technical problem. Thus, the expertise of others can be sought by clearly stating the problem. While the latter approach is more similar to knowledge integration as a process of knowledge transfer, the first two resemble knowledge integration as a process aimed at a synthesis of disparate specialized knowledge. Despite these insights, it seems that knowledge integration processes in product development are still poorly understood (Foos et al., 2006). Consequently, the underlying approaches to knowledge integration in collaborative buyer - supplier relationships require further investigation.

To shed more light upon the approaches to knowledge integration, we make a distinction between knowledge sharing and knowledge combining (Okhuysen and Eisenhardt, 2002). Knowledge sharing is defined as a process where "individuals identify and communicate their uniquely held information" (Okhuysen and Eisenhardt, 2002, p. 383). This view needs to be clearly distinguished from common knowledge which refers to "shared belief systems" (Dixon, 2000). In knowledge integration processes these two perspectives often merge, i.e. revealing part of an actors' knowledge could result in common knowledge that is known throughout the actors' organizations. However, here we emphasize knowledge sharing as a crucial first step in knowledge integration processes. The definition of 
knowledge sharing indicates the importance of communication. Here, Okhuysen and Eisenhardt (2002) demonstrated in a laboratory setting that communication in knowledge sharing creates unfavorable conditions for creating synergies based on the knowledge held by individuals. This indicates that more communication may not always affect knowledge sharing positively. Rather, a constructive communication climate is required in which openness, accessibility and cooperative interaction are important prerequisites for knowledge sharing (Hooff and Ridder, 2004). As a second step in a knowledge integration process, knowledge combining refers to a situation in which several individuals combine their knowledge to create something new (Okhuysen and Eisenhardt, 2002). This process is more complex than knowledge sharing and relies on joint problem-solving, questioning others and different ways of knowing. The combination of knowledge depends on how individuals know, consider alternative combinations and use different lenses to view their own and others' knowledge. As knowledge sharing and knowledge combining are both important in knowledge integration, in this paper, we conceptualize knowledge integration as a process that starts with knowledge sharing and subsequently and perhaps also partly in parallel focuses on combining specialized knowledge. It is expected that this process will result in the creation of new knowledge through synthesis (Tell, 2011).

\section{Mechanisms for knowledge integration}

Many researchers have emphasized the importance of managing knowledge in organizations, specifically in relation to tacit knowledge relying on personal skills that are difficult to transfer (Kumar and Ganesh, 2011; Ranucci and Souder, 2015; Foos et al., 2006). When scrutinizing existing literature, a wide range of mechanisms for establishing knowledge integration can be identified (Berggren et al., 2011). Each of these mechanisms provides different prerequisites for interaction between individuals. Grant (1996) proposes several mechanisms, including rules and directives, sequencing, routines and group problem-solving and decision-making. Rules and directives involve plans, schedules, forecasts, policies and procedures. Sequencing relies on organizing the work in a time-patterned sequence to minimize dependencies. In NPD, for example, this thought is represented in stage-gate development models (Cooper, 2008; Gronlund et al., 2010). Another mechanism is based on routines, i.e. stable patterns of behavior that characterize organizational reactions and are developed through experience accumulation, knowledge articulation and knowledge codification processes (Zollo and Winter, 2002). Finally, group problem-solving and decision-making is a communication-intensive form of integration, relying upon high levels of interaction and seems to be especially important when task complexity is high and when knowledge cannot be easily articulated. Schmickl and Kieser (2008) propose additional mechanisms that facilitate knowledge integration and reduce the need for extensive communication and transfer of knowledge between specialists. First, transactive memory involves knowing and being able to identify specialists (Akgun et al., 2006). Transactive memory essentially constitutes a shortcut in the search for external knowledge. Second, modularization allows the breakdown of large and complex tasks into smaller subtasks. This limits the problem- solving to specific interface issues and allows sequencing in NPD processes. Third, experts could also use prototypes to identify specific challenges or problems related to the interaction of several product components.

\section{Knowledge characteristics and knowledge integration}

The broad range of possible knowledge integration mechanisms presumably indicates that different mechanisms are effective in different situations. Difficulties in relation to knowledge integration have frequently been related to the dichotomy between tacit and explicit knowledge (Kogut and Zander, 1992; Conner and Prahalad, 1996; Nonaka, 1994). In buyer - supplier collaborations, explicit knowledge may be integrated through exchanges of relatively small-scale technical information, for example, to solve problems and enhance products and processes, whereas tacit knowledge integration requires 
large-scale commitments in concerted projects (Kotabe et al., 2003). Knowledge integration activities based on small-scale technical information are exploitative in character (Faems et al., 2005) and focus on the refinement and extension of existing competences and technologies. In this context, suppliers may be important external knowledge sources for incremental innovation by initiating and enabling improvements to product quality and decreased costs (Belderbos et al., 2004; Hoegl and Wagner, 2005). To a large extent, these inputs rely on explicit knowledge. In contrast, suppliers can also contribute to radical innovation, such as innovative design and technology solutions (Schiele, 2006; Un et al., 2010). Radical innovation relies to a higher degree on explorative processes and tacit knowledge integration through search, discovery and experimentation (Cheng and Van de Ven, 1996) and is associated with increased commitments and concerted efforts (Kotabe et al., 2003). Studies of product development projects show that radical projects are managed in a different way than incremental projects (Holahan et al., 2014). Consequently, it can be asserted that the character of the external supplier knowledge input into product development processes also influences the practices related to the use of knowledge integration approaches and mechanisms in product development processes.

\section{Methodology}

\section{Research design}

To explore the knowledge integration approaches and mechanisms that are used to integrate suppliers' external knowledge into NPD projects, we designed our research as a multiple case study of six projects at three international manufacturing firms offering complex products to an industrial market. Case studies were considered to be an appropriate approach, as the aim was to gain an in-depth understanding of the phenomenon - knowledge integration - in its context (Eisenhardt, 1989). Therefore, the research design relies on a multiple case that follows a logic of theoretical replication and allowed us to investigate the phenomenon in different industries (Yin, 2009).

To find relevant cases, only firms with relatively high levels of R\&D activity were included in the study. These firms generally attach a higher value to collaborating partners and tend to have a higher absorptive capacity than less high-tech firms (de Faria et al., 2010). One firm, called Carcom, was selected from the automotive industry. Carcom is a relatively small player in this industry, with approximately 2,350 employees and an R\&D spend of 3.3 per cent of sales. The second firm, Telcom, is a considerably larger and world-leading firm in the telecoms industry, with an R\&D spend of 14.4 per cent. The number of employees is about 100,000. The third firm is called Enercom and is active in the energy sector. This firm has about 130,000 employees and an R\&D spend of 3.7 per cent.

In close collaboration with these three firms and following discussions with strategic managers at the respective firms, two NPD projects were selected at each firm (Table I). Each of the NPD projects took place over two-three years and involved about ten project members from the three different firms, together with several employees from the suppliers. One of these projects was characterized as incremental, primarily building on incremental knowledge inputs from the suppliers. The other project at each firm was characterized as more exploratory and radical in nature, using radical knowledge inputs from suppliers. This allowed us to explore potential differences in knowledge integration approaches and mechanisms for these different types of projects.

The radical or incremental nature of the projects was determined in collaboration with the strategic managers at the three firms in relation to the degree of familiarity with the given technologies, i.e. technological novelty (Tatikonda and Rosenthal, 2000). In projects with supplier input that was radical in nature, i.e. the holder, battery and antenna project, the supplier contributed knowledge that related to new technology and/or a completely new design that had not previously been implemented in a similar product. In the projects with 
Table I Selection of the cases

\begin{tabular}{|c|c|c|}
\hline Carcom & Enercom & Telcom \\
\hline \multicolumn{3}{|l|}{ Radical supplier input } \\
\hline Holder & Battery & Antenna \\
\hline $\begin{array}{l}\text { Component in disc } \\
\text { brake }\end{array}$ & $\begin{array}{l}\text { Battery development for high } \\
\text { voltage application }\end{array}$ & Active antenna system \\
\hline $\begin{array}{l}\text { Supplier specialized in } \\
\text { casting }\end{array}$ & $\begin{array}{l}\text { Supplier of advanced battery } \\
\text { technology }\end{array}$ & $\begin{array}{l}\text { Supplier specialized in } \\
\text { antenna technology }\end{array}$ \\
\hline \multicolumn{3}{|l|}{ Incremental supplier input } \\
\hline Caliper & Bearing & Processor \\
\hline $\begin{array}{l}\text { Critical component in } \\
\text { disc brake }\end{array}$ & Hybrid bearing & Computer platform \\
\hline $\begin{array}{l}\text { Specialized supplier in } \\
\text { casting and processing }\end{array}$ & $\begin{array}{l}\text { Supplier specialized in } \\
\text { bearing technology and } \\
\text { applications }\end{array}$ & $\begin{array}{l}\text { Supplier specialized in } \\
\text { processor technology }\end{array}$ \\
\hline
\end{tabular}

incremental supplier knowledge inputs, i.e. the caliper, bearing and processor project, the suppliers' knowledge was used to produce improved products/processes and focused on limited changes in technology or design.

\section{Data collection and analysis}

As all NPD projects were in a final phase when the data collection began, we could easily gain an overview of the projects and had access to extensive empirical material. Research data was primarily collected through interviews, which is a highly efficient method for gathering detailed data (Eisenhardt and Graebner, 2007). By selecting individuals with different roles and responsibilities and having access to and detailed knowledge about the NPD projects, representativeness and quality were ensured. The main part of the interviews was carried out at the three firms with strategic purchasing staff, project managers, designers, manufacturing engineers and other key personnel involved in the collaboration with suppliers in the projects. Project managers, engineers and key account managers from the suppliers were interviewed. These provided additional insights and validated the findings from the buying firms' perspective. In total, 46 interviews were conducted (Table II), almost all face-to-face to get descriptions that were as rich as possible. Each interview lasted on average $1 \mathrm{~h}$.

The data analysis was carried out by classifying the narratives into content categories using the theoretical framework - to structure the data. This was based on general predetermined categories, such as the type of supplier input (e.g. the knowledge characteristics), the knowledge integration approaches (e.g. emphasis on transfer or synthesis) and the knowledge integration mechanisms from the theoretical framework. This way of working enabled us to find additional new themes. Acknowledging different types of supplier inputs, the focus was initially on identifying the knowledge integration mechanisms. Then the different ways of integrating knowledge were identified and

\section{Table II Overview of interviews}

\begin{tabular}{llcl} 
Company & \multicolumn{1}{l}{ Case } & No. of interviews & Interview time \\
\hline CARCOM & Case 1: The holder & 5 & $4 \mathrm{~h} 15 \mathrm{~min}$ \\
& Case 2: The caliper & 5 & $4 \mathrm{~h} 20 \mathrm{~min}$ \\
ENERCOM & Case 3: The battery & 10 & $14 \mathrm{~h}$ \\
& Case 4: The bearing & 11 & $16 \mathrm{~h} \mathrm{30} \mathrm{min}$ \\
TELCOM & Case 5: The antenna & 9 & $11 \mathrm{~h} 10 \mathrm{~min}$ \\
& Case 6: The processor & 6 & $6 \mathrm{~h}$ \\
Total: & & 46 & $56 \mathrm{~h} 15 \mathrm{~min}$
\end{tabular}


characterized by identifying the associated knowledge integration approaches in each of the cases. Subsequently, a comparative analysis was carried out by listing similarities and differences. This comparison is presented in Table III and allows the reader to draw their own conclusions (Miles and Huberman, 1994). From the cross-case analysis, two distinct approaches for integrating knowledge into collaborative NPD projects with suppliers emerged from the empirical material. These, together with relationships to the specific knowledge characteristics, will be discussed further in the analysis and discussion section.

\section{Results - knowledge integration with suppliers in six new product development projects}

\section{Case 1 - the holder (Carcom)}

The holder is a critical component in the development of a new generation of disc brakes. To develop this component, a completely new solution and new innovative design was necessary. This solution deviates extensively from previous designs that are available on the market. For this purpose, Carcom involved a supplier with specific expertise in casting design and processing. This involved the integration of knowledge based on far, or potentially strategic, knowledge integration due to the system-wide implications of the new component (Dixon, 2000). The supplier was involved throughout the project, and together with Carcom, deep analyses of the component were made based on the joint interpretation of knowledge gained from previous projects:

The supplier has been involved throughout the whole holder project. They have also been involved in previous development projects and thus have experience that they could bring to this new project. We have succeeded in transferring knowledge from past projects into this project (Engineer, Carcom).

Carcom and the supplier characterize their collaboration by openness and interpersonal contacts. Throughout the process, problems and challenges were solved jointly:

We have been deeply involved in this. Normally we get a drawing that directs our work. In this case, we have been working very closely with the designers and together we have tried to optimize the component (Engineer, Supplier).

Throughout an extended period of time, iterations in the processes of sharing and combining knowledge took place. Triggered by new challenges, new knowledge was revealed and subsequently combined into the evolving solution. This extended and evolving process of knowledge integration continued even after the NPD project was finalized. One of the success factors was, according to the two firms, related to the scope of the knowledge input of the supplier. Although specialized in casting, the supplier did typically also contribute knowledge related to processing. This points to the importance of common joint knowledge in knowledge integration processes characterized by far or strategic transfer and focused on the joint interpretation of knowledge to result in new combinations based on synthesis. The knowledge input of the supplier exceeded its future tasks in manufacturing.

\section{Case 2 - the caliper (Carcom)}

The caliper is a critical component in a disc brake. Calipers are used to squeeze pairs of pads against a disc to create friction that retards the rotation of a shaft, such as a vehicle axle. The new development included a number of innovative features affecting the casting design. Carcom involved a new, very large and well-known specialist manufacturer of disc-break components in its development project. The supplier had critical manufacturing competence and was considered to be one of the major future suppliers of the caliper. The input of supplier knowledge was considered to be incremental and the involvement of the supplier was foremost during the development phase of the NPD project. Knowledge integration with this supplier could be characterized as expert integration (Dixon, 2000). 


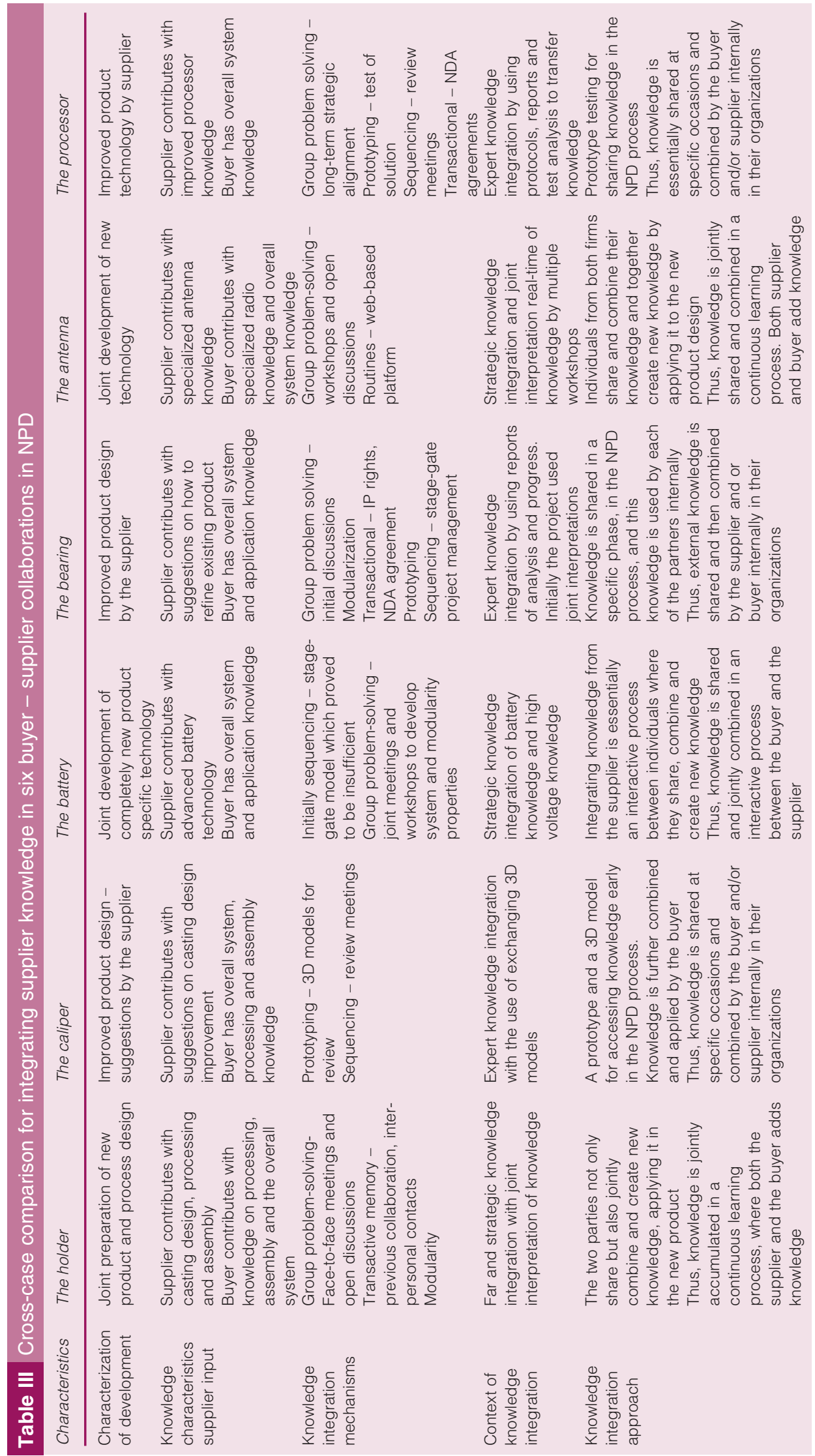


Carcom shared its knowledge by exchanging 3D models. The supplier reviewed these and provided Carcom with feedback and suggestions. The 3D models served as artifacts for sharing knowledge:

In the caliper project we have sent 3D models to the supplier. They then import this model into their own CAD system and change the modules into something they are able to cast. Thereafter we get the model back. From there it's all about finding a compromise, to get the best variant where the function and casting is at its best. This dialogue with the supplier has been deep (Project Manager, Carcom).

The supplier's knowledge in casting served as a critical input:

Particularly in the development phase, we have to react and give feedback to Carcom. In that way, if necessary we can change a tolerance or design and geometry, so this is integrated later (Engineer, Supplier).

The new design also had an impact on the further processing and assembly of the component in the system. However, the supplier was not involved in discussing processing possibilities and limitations. The interaction was focused on optimizing the detailed specifications and design of the component.

\section{Case 3 - the battery (Enercom)}

The firm of Enercom acts as a system integrator in the energy sector and provides large industrial systems to the market. In the battery project, Enercom was aiming to develop a new energy storage solution for high voltage applications. Battery technology was considered critical in this solution and a co-development project was initiated with a specialist supplier. Enercom had little knowledge about batteries and their properties, whereas the supplier knew little about high voltage applications. The new solution needed to build strongly on the integration of both battery knowledge and high voltage application knowledge and resembles a situation of strategic knowledge transfer (Dixon, 2000). Enercom initially used a stage-gate project management approach to manage the involvement of the supplier. It relied largely on interaction with the supplier in project review meetings in which progress was discussed. However, after a while, the engineers felt that there were too few opportunities for interaction and joint development of solutions. To facilitate the development of a joint understanding of the constraints, the project was further organized through a number of joint meetings and workshops. An important focus was to develop the interface between the batteries and the electrical system:

We wanted to have a clear division of labor, so that there would be no confusion about what belonged to Enercom and what belonged to the supplier. Also, we did not want the supplier to learn everything from us and then go to one of our competitors and start selling the batteries (Project Manager, Enercom).

During the joint meetings and workshops, project members at Enercom learned about the battery solution and its limitations. Meanwhile, the supplier learned more about the constraints related to the surrounding system and its application. Together, they jointly created new and specific knowledge that they did not previously have.

We focus on the batteries and mechanical/electrical structure surrounding the batteries, whereas Enercom's focus is on the integration into containers. Everything affecting the interfaces needs to be shared between the firms (Project Manager, Supplier).

\section{Case 4 - the bearing (Enercom)}

In another division of Enercom, a project was initiated to develop a hybrid bearing. This bearing was intended for use in electrical motors in trains. The hybrid bearing is a highly modular component in Enercom's overall system. The technological knowledge and intellectual property rights resided in a large and specialized supplier. Enercom has a 
long-standing relationship with this supplier and the two firms were well aware of each other's technical and organizational capabilities.

The interaction between Enercom and the supplier took place mainly through joint meetings and telephone conferences. Iterative discussions were initiated focusing on the functional specifications of the hybrid bearing. The discussions focused on Enercom's demands in relation to the limitations of the design by the supplier. To clarify why the supplier could not fully meet Enercom's demands, the supplier shared in-depth knowledge about the design of the hybrid bearing. Enercom shared knowledge about the overall system and applications in train motors, especially concerning its expectations related to maintenance and life expectancy. The supplier was hoping to use this knowledge to improve its future offerings for similar customers:

The possibility of further building our knowledge has been an advantage to us [in this project]. Collaborating with Enercom, which is in the frontline and has a new way of thinking is positive for us. It is useful for us, not only by increasing our business but also in terms of knowledge (Manager, Product Management and Business Development, Supplier).

Consequently, knowledge integration was characterized by expert knowledge integration with initially joint interpretation of knowledge (Dixon, 2000) in a knowledge-sharing phase. However, once the specifications were agreed upon, the development was performed by the supplier based on little interaction with Enercom. The supplier manufactured several pilot series of the hybrid bearings that were tested on motors. Enercom provided data on this testing to the supplier. Based on this data, the supplier modified and optimized the bearing solution.

Our general knowledge of bearings has increased due to the collaboration with the supplier. In particular, our knowledge of interpreting and understanding demands on the bearings and what implications they have on the product has increased (Project Manager, Enercom).

\section{Case 5 - the antenna (Telcom)}

The antenna project aimed at developing an active antenna based on a combination of two technologies related to radio and antenna. The idea for the project originated from the supplier, which is a well-known firm in the market and which specializes in antennas. The supplier established contact with Telcom and suggested co-developing the product. The knowledge residing in the antenna supplier and Telcom's knowledge were equally important in the realization of the product. Knowledge integration was therefore based on joint interpretation of knowledge (Dixon, 2000). This way of working was clearly different from their previous collaborations:

In previous collaborations we received a spec and could influence the project slightly. However, in this project, we created the product together (Project Manager, Supplier).

During the project, the interaction between the two firms was extensive. In the design phase, the firms organized two-day workshops every two weeks. Ten individuals participated in these workshops, five from each firm. During this period, the employees from each firm became one team. Additional contacts were numerous through telephone conferences, e-mails and documents that were exchanged on a shared web-based platform. Telcom organized the project through its established processes for product development, whereas the supplier relied less on structure and emphasized the importance of flexibility. The problems and challenges in the project were solved by having open communication and discussions:

People belonging to different technological areas trusted each other. That's important for the development of the interfaces. We have to be open to new solutions to develop the product

(Platform Manager, Telcom). 


\section{Case 6 - the processor (Telcom)}

The processor project focused on the development of a generic computer platform for a new generation of products. Telcom chose to continue to collaborate with the supplier of previous generations of the processor. This supplier is a market leader in the processor industry. The supplier pushes technology and product development independently. Based on its own product portfolio, it developed an offering to meet Telcom's specific demands.

To leverage this offering, Telcom allocated an internal team that worked with the processor project and its integration into Telcom's overall system. Telcom provided the supplier with demands and focused on influencing the longer-term design of the supplier's next generation of products. When the supplier released its prototype to Telcom, the supplier's product architecture engineers met Telcom's team. In this meeting, the supplier analyzed which parts of the component were critical to Telcom and proposed a final solution that could be tested. Telcom's internal team focused on implementing the supplier's solution into their system, testing it and providing feedback to the supplier. The supplier's role in the knowledge integration process resembled that of an expert (Dixon, 2000). During the development project, interaction between the firms took place in design review meetings. This interaction was of a technical nature focused on progress reports and clarifications:

We have weekly meetings where we follow up the progress of the project and what difficulties we have. The supplier provides us with answers (Project Manager, Telcom).

The supplier allowed Telcom little insight into the technical details of its design. Simultaneously, Telcom was not inclined to disclose details about its technologies and system designs beyond those that the supplier needed to know to provide a suitable solution. Consequently, the sharing of knowledge between the two firms was limited.

[...] we are surrounded by IP and patent infringement. You don't want to show what you are doing. That makes engineer-to-engineer discussions rather limited (Key Account Manager, Supplier).

\section{Analysis and discussion}

\section{Emerging patterns of knowledge integration}

All six NPD projects represent a unique story about how external knowledge is integrated. However, the cases reveal several patterns that characterize the knowledge integration process in the projects. To describe these, the cross-case analysis focuses on knowledge characteristics in terms of supplier input in relation to knowledge integration mechanisms and corresponding knowledge integration approaches. To start with the knowledge characteristics, the cases were selected to show variations in the knowledge input of suppliers. As such, incremental input, i.e. knowledge for improved products/processes (Belderbos et al., 2004; Hoegl and Wagner, 2005), or more radical input, i.e. supplier input in terms of new technology/design (Un et al., 2010; Li and Vanhaverbeke, 2009; Schiele, 2006), was determined by our research design. However, the analysis of the data further informed us about the knowledge characteristics of the suppliers' input and the type of knowledge integration in relation to similarities and differences in knowledge (Dixon 2000) (Table III). The three buying firms each acted as system integrators for larger and complex systems for industrial markets and their overall system knowledge was critical in the process of integrating external knowledge into the projects (Takeishi, 2001). However, the knowledge of each of the suppliers in terms of task and context in which it operates varied considerably.

The input from the suppliers was characterized as incremental in three of the projects. These inputs considered suggestions for pre-existing designs of the buying firm or minor changes to the suppliers' own existing products. In each of these three collaborations, the buying firms chose to collaborate with large, well-known, specialized suppliers with a dominant market position and potential exposure to direct competitors of the buying firms. 
In these projects, the suppliers acted as providers of expert knowledge (Dixon, 2000). A range of media were used to transfer knowledge, such as 3D models, reports, protocols and test analysis results. However, to gain a shared understanding of the project's goal, one of the incremental projects also made use of joint interpretation of knowledge in an initial phase of the project. Moreover, although the potential value of the suppliers' external knowledge was acknowledged, the customers were aware of the risk of knowledge leakage, and this may have limited the openness of the firms (Oxley and Sampson, 2004; Heiman and Nickerson, 2004) in terms of knowledge integration. The knowledge characteristics in the radically characterized projects represented supplier inputs relating to the suppliers' highly specialized component technology input. In contrast to the projects with incremental supplier input, the newly developed products in these projects relied to a higher degree on jointly developed, customized solutions and thus on a higher degree of asset specificity (Williamson, 1979). The collaborations relied to a greater degree on far and strategic knowledge integration and joint processes based on a certain degree of common knowledge (Dixon, 2000). The projects made use of real-time interpretations in physical meetings and problem-solving workshops where knowledge was combined from the buying firm and the supplier to find technical solutions.

Further comparison of the projects reveals that a wide range of knowledge integration mechanisms was used in the projects. In the projects with incremental input, not only sequencing and prototyping in particular but also modularization and transactional governance were dominant (Table III). To a small extent, knowledge integration also took place through group problem-solving in these projects, usually during a limited period of time. In sequencing, traditional stage-gate models in NPD processes were utilized (Cooper, 2008). Clear specifications directed the input from the suppliers to specific phases in the process. In addition, status updates were used at gates in the product development process to follow-up and monitor the progress made. The three projects also widely used prototypes to identify potential problems in the product solutions and to evaluate the interaction of the component with the overall system design (Schmickl and Kieser, 2008). In the projects with radical supplier input, group problem-solving was prevalent as a mechanism for knowledge integration. The collaboration in these projects relied on regular joint meetings and open discussions throughout an extended period of time during the projects and allowed an interactive way of working (Grant, 1996). In several of the projects, group problem-solving was supported by transactive memory based on previous collaborations. Group problem-solving was also facilitated by common working routines in terms of a web-based platform. One of the radical projects initially relied on a stage-gate project management approach (Gronlund et al., 2010; Cooper, 2008). This mechanism was eventually abandoned and replaced by group problem-solving, as the project team realized that the initial approach provided insufficient support for knowledge integration in the particular project.

The pattern of knowledge integration mechanisms in the three projects with incremental input could be interpreted as a purposeful approach aimed at balancing openness in external knowledge integration with a control of knowledge flows to protect valuable technology (Oxley and Sampson, 2004). The mechanisms that were used required a limited degree of personal communication, provided a clear structure for integration and were accompanied by a complementary focus on transactional governance. Sequencing, modular designs, prototyping and NDA agreements were used to facilitate knowledge sharing while prohibiting unintended knowledge leakage (Schmickl and Kieser, 2008). The subsequent combination of knowledge was carried out more or less independently by the buyer firm's internal engineering team. In contrast, in the projects with radical supplier input, the boundaries of the firm were stretched by allowing in-depth and interpretive group problem-solving between the individuals of the different firms in the project. In line with previous literature, group problem-solving was found to be suitable for more complex tasks (Grant, 1996), based on a high degree of communication between individuals (Galbraith, 
1977) and particularly useful for experimentation with new alternatives in exploratory processes (March, 1991). A relational perspective, transactive memory and supportive routines were used as complementary mechanisms. These projects were characterized by an explicit reciprocity of knowledge sharing, i.e. both the supplier and the buyer provided indispensable knowledge input to the project, and there was a joint process for combining the different knowledge bases.

\section{Two approaches for integrating external knowledge}

Based on this comparative analysis, two distinct approaches for integrating external knowledge emerge. Both approaches emphasize revealing the presence of pertinent knowledge rather than transmitting it entirely (Tiwana and McLean, 2005). The first approach was found in combination with knowledge characteristics that represent incremental supplier input based on explicit knowledge in terms of refinements and extensions of existing product designs, which have been discussed in previous research by Belderbos et al. (2004) and Hoegl and Wagner (2005). Knowledge integration in these contexts requires small-scale commitments (Kotabe et al., 2003). Collaborative activities take place through rather impersonalized knowledge integration mechanisms, providing a sufficient basis for knowledge sharing while preventing the boundaries of the firm from becoming too open and safeguarding against knowledge leakage (Oxley and Sampson, 2004). The main purpose of external knowledge integration could be described as the capturing of knowledge from the other partner through mechanisms that allow knowledge sharing. This provides an avenue for firms to obtain access to complementary knowledge (Grant and Baden-Fuller, 2004). The subsequent combination of knowledge occurs in a rather shielded and independent manner in the respective buyer and supplier organizations. It could be argued that this knowledge integration approach provides advantages related to the efficiency of integration (Grant, 1996; Grant and Baden-Fuller, 2004; Schmickl and Kieser, 2008) as well as limiting the risk of knowledge leakage (Heiman and Nickerson, 2004; Oxley and Sampson, 2004). We label this approach decoupled knowledge integration (Figure 1).

The second approach was found in combination with more radical supplier input knowledge characteristics. This approach relies on joint processes, in which knowledge is shared and combined in an interactive process focused on the interpretation of knowledge (Huang and Newell, 2003; Dixon, 2000). Past experience and trust and a certain degree of overlapping knowledge (Takeishi, 2001) appear to be important in these knowledge integration processes. The foremost knowledge integration mechanism used is group problem solving. The boundaries of the firms are relatively open. As knowledge sharing and combining takes place interactively, it allows individuals from both buyer and supplier, with

\section{Figure 1 Coupled and decoupled knowledge integration}

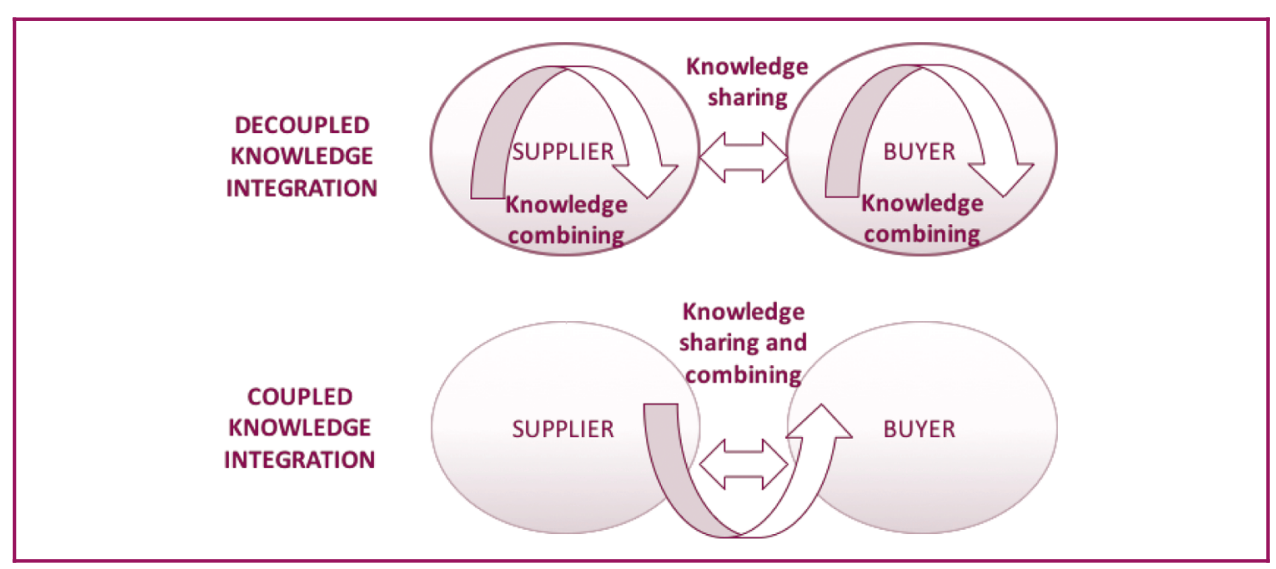

VOL. 21 NO. 52017 JOURNAL OF KNOWLEDGE MANAGEMENT | PAGE 1047 
distinct knowledge bases, to experiment with new ideas to create and apply new knowledge (Cheng and Van de Ven, 1996; March, 1991). Knowledge is not primarily considered as a resource but as knowing. We label this approach coupled knowledge integration, and outline its characteristics in Figure 1.

\section{Conclusions}

To study how firms open up their boundaries when integrating external knowledge, we set out to study six NPD projects at three knowledge-intensive manufacturing firms. By doing so, it was possible to investigate the approaches that firms use for integrating knowledge with their suppliers. We conceptualize knowledge integration as a process consisting of two sub-processes, i.e. knowledge sharing and knowledge combining. Based on our results, we were able to identify and characterize two different approaches:

1. a decoupled approach to knowledge integration in which knowledge sharing and knowledge combining are treated as two separate sub-processes; and

2. a coupled approach to knowledge integration based on coupled knowledge sharing and combining across firms.

Each of the approaches has specific implications in terms of how knowledge integration is managed, the perspective on knowledge, the similarities of knowledge bases and the openness of firm boundaries. The two approaches are characterized in Table IV.

Based on the results of our study, we propose that firms make purposeful choices to devise knowledge integration approaches when working in collaborative buyer - supplier projects. First, these purposeful choices should be guided by the knowledge characteristics of the supplier input (i.e. radical or incremental) that reflect the knowledge of the supplier in relation to the specific demands of the product development task. In line with previous studies that stress the fact that knowledge characteristics help to explain how collaboration activities are implemented (Ranucci and Souder, 2015; Foos et al., 2006), we find decoupled knowledge integration approaches to be connected to incremental supplier inputs based on improved products and/or processes and limited changes in technology and design. Although knowledge integration with suppliers is necessary to achieve the objectives in these projects, firms seem to limit their openness by allowing knowledge to be shared across firm boundaries but by being inclined to perform combining internally. This implies that whenever the task makes it possible, firms try to capture the value of the suppliers' external knowledge, in line with the resource-based view of the firm (Barney, 1991; Dyer and Singh, 1998), but do not disregard the potential risks of opportunism in inter-firm transactions of knowledge (Grandori, 2001; Oxley and Sampson, 2004). In contrast, when the task does not allow limitations on the openness of firm boundaries, we propose that firms use coupled approaches to knowledge integration by jointly sharing and combining knowledge across firm boundaries. Therefore, we argue that an understanding of how to integrate external knowledge into NPD projects needs to be based on complementary perspectives building on the knowledge-based view, i.e. the integration of knowledge is considered as a problem of cognitive limitations and coordination (Kogut and

Table IV Knowledge integration approaches characterized

\begin{tabular}{lll} 
Dimensions & Decoupled & Coupled \\
\hline Knowledge sharing & Cross-firm & Cross-firm \\
Knowledge combining & Within firm & Cross firm \\
Openness boundaries of the firm & Semi-permeable & Permeable \\
Dominant perspective on knowledge & Resource & Knowing \\
Knowledge characteristics supplier input & Incremental & Radical \\
Knowledge integration focus & Explicit & Interpretation \\
& & and synthesis
\end{tabular}


Zander, 1992; Conner and Prahalad, 1996) and on organizational economics (Williamson, 2002).

Our study extends the existing literature that either considers knowledge integration as a transfer of knowledge or as based on revealing the presence of pertinent knowledge without transmitting it entirely (Huang and Newell, 2003; Okhuysen and Eisenhardt, 2002). We outline approaches to knowledge integration that include elements of both, but provide a more complex picture connected to the knowledge characteristics, perspectives of knowledge, openness of firm boundaries and elements of knowledge sharing and combining. Consequently, our study refines the results of previous studies that point to the limits of openness (Laursen and Salter, 2014; Laursen and Salter, 2006) by showing that firms make choices by adjusting their knowledge integration processes following the specific demands of the NPD task and the knowledge of the suppliers.

The study has been carefully designed so that we were able to make inferences from our data; however, we studied only six cases. The results show a consistent pattern, but it cannot be excluded that studying more diverse cases might result in additional insights. For instance, we only studied incremental knowledge inputs in incremental NPD projects and radical knowledge inputs in radical NPD projects, i.e. projects designed mainly around the specific collaboration. However, it is not uncommon for several suppliers or other actors to be involved in a single NPD project (Lakemond et al., 2006). Furthermore, smaller technology-based firms from other sectors could also be studied. Knowledge integration processes in these firms are situated in a context of innovation that is characterized by a high degree of complexity and uncertainty (Berggren et al., 2011). This context is different from that discussed by Grant (1996) and his knowledge-based theory of the firm, which assumes that the primary role of the firm is the application of existing knowledge. Further research could possibly add additional insights and further validate the results of this study.

\section{References}

Akgun, A.E., Byrne, J.C., Keskin, H. and Lynn, G.S. (2006), "Transactive memory system in new product development teams", IEEE Transactions on Engineering Management, Vol. 53 No. 1, pp. 95-111.

Alavi, M. and Tiwana, A. (2002), "Knowledge integration in virtual teams: the potential role of KMS", Journal of the American Society for Information Science and Technology, Vol. 53 No. 12, pp. 1029-1037.

Barney, J. (1991), "Firm resources and sustained competitive advantage", Journal of Management, Vol. 17 No. 1, pp. 99-120.

Belderbos, R., Carree, M. and Lokshin, B. (2004), "Cooperative R\&D and firm performance", Research Policy, Vol. 33 No. 10, pp. 1477-1492.

Berggren, C., Bergek, A., Bengtsson, L., Hobday, M. and Söderlund, J. (2011), Knowledge Integration and Innovation - Critical Challenges Facing International Technology-based Firms, Oxford University Press, Oxford.

Brown, S.L. and Eisenhardt, K.M. (1995), "Product development: past research, present findings, and future directions", The Academy of Management Review, Vol. 20 No. 2, pp. 343-378.

Carlile, P.R. (2002), "A pragmatic view of knowledge and boundaries: boundary objects in new product development”, Organization Science, Vol. 13 No. 4, pp. 442-455.

Carlile, P.R. (2004), "Transferring, translating, and transforming: an integrative framework for managing knowledge across boundaries", Organization Science, Vol. 15 No. 5, pp. 555-568.

Cheng, Y. and Van de Ven, A.H. (1996), "Learning the innovation journey: order out of chaos?", Organization Science, Vol. 7 No. 6, pp. 593-614.

Chesbrough, H. (2003), Open Innovation - The New Imperative for Creating and Profiting From Technology, Harvard Business School Press, Boston, MA. 
Conner, K.R. and Prahalad, C.K. (1996), "A resource-based theory of the firm: knowledge versus opportunism", Organization Science, Vol. 7 No. 5, pp. 477-501.

Cooper, R.G. (2008), "Perspective: the Stage-Gate ${ }^{\circledR}$ idea-to-launch process - update, what's new, and NexGen systems", Journal of Product Innovation Management, Vol. 25 No. 3, pp. 213-232.

Cousins, P.D., Lawson, B., Petersen, K.J. and Handfield, R.B. (2011), "Breakthrough scanning, supplier knowledge exchange, and new product development performance", Journal of Product Innovation Management, Vol. 28 No. 6, pp. 930-942.

Dahlander, L. and Gann, D.M. (2010), "How open is innovation?", Research Policy, Vol. 39 No. 6, pp. 699-709.

de Faria, P., Lima, F. and Santos, R. (2010), "Cooperation in innovation activities: the importance of partners", Research Policy, Vol. 39 No. 8, pp. 1082-1092.

de Man, A.-P. and Duysters, G. (2005), "Collaboration and innovation: a review of the effects of mergers, acquisitions and alliances on innovation", Technovation, Vol. 25 No. 12, pp. 1377-1387.

Dixon, N.M. (2000), Common Knowledge: How Companies Thrive by Sharing What They Know, Harvard Business School Press.

Dyer, J.H. and Singh, H. (1998), "The relational view: cooperative strategy and sources of interorganizational competitive advantage", Academy of Management Review, Vol. 23 No. 4, pp. 660-679.

Eisenhardt, K.M. (1989), "Building Theories from Case-Study Research", Academy of Management Review, Vol. 14 No. 4, pp. 532-550.

Eisenhardt, K.M. and Graebner, M.E. (2007), "Theory building from cases: opportunities and challenges", Academy of Management Journal, Vol. 50 No. 1, pp. 25-32.

Faems, D., Van Looy, B. and Debackere, K. (2005), "Interorganizational collaboration and innovation: toward a portfolio approach*", Journal of Product Innovation Management, Vol. 22 No. 3, pp. 238-250.

Foos, T., Schum, G. and Rothenberg, S. (2006), "Tacit knowledge transfer and the knowledge disconnect", Journal of Knowledge Management, Vol. 10 No. 1, pp. 6-18.

Galbraith, J.R. (1977), "Organization design”, Addison-Wesley Pub. Co.

Galunic, D.C. and Rodan, S. (1998), "Resource recombinations in the firm: knowledge structures and the potential for Schumpeterian innovation", Strategic Management Journal, Vol. 19 No. 12, pp. 1193-1201.

Grandori, A. (2001), "Neither hierarchy nor identity: knowledge-governance mechanisms and the theory of the firm", Journal of management and Governance, Vol. 5 Nos 3/4, pp. 381-399.

Grant, R.M. (1996), "Toward a Knowledge-Based Theory of the Firm", Strategic Management Journal, Vol. 17, pp. 109-122.

Grant, R.M. and Baden-Fuller, C. (2004), "A knowledge accessing theory of strategic alliances", Journal of Management Studies, Vol. 41 No. 1, pp. 61-84.

Gronlund, J., Sjodin, D.R. and Frishammar, J. (2010), "Open innovation and the stage-gate process: a revised model for new product development", California Management Review, Vol. 52 No. 3, pp. 106-131.

Hayek, F. (1945), "The use of knowledge in society", The American Economic Review, Vol. 35 No. 4 , pp. 519-530.

Heiman, B.A. and Nickerson, J.A. (2004), "Empirical evidence regarding the tension between knowledge sharing and knowledge exproproation", Strategic Management Journal, Vol. 25 Nos 8/9, pp. 723-749.

Hoegl, M. and Wagner, S.M. (2005), "Buyer-supplier collaboration in product development projects", Journal of Management, Vol. 31 No. 4, pp. 530-548.

Holahan, P.J., Sullivan, Z.Z. and Markham, S.K. (2014), "Product development as core competence: how formal product development practices differ for radical, more innovative, and incremental product innovations", Journal of Product Innovation Management, Vol. 31 No. 2, pp. 329-345. 
Hooff, B.V.d. and Ridder, J.A.D. (2004), "Knowledge sharing in context: the influence of organizational commitment, communication climate and CMC use on knowledge sharing", Journal of Knowledge Management, Vol. 8 No. 6, pp. 117-130.

Huang, J. and Newell, S. (2003), "Knowledge integration processes and dynamics within the context of cross-functional projects", International Journal of Project Management, Vol. 21 No. 3, pp. 167-176.

lansiti, M. (1995), "Technology integration: managing technological evolution in a complex environment", Research Policy, Vol. 24 No. 4, pp. 521-542.

Knudsen, M.P. and Mortensen, T.B. (2011), "Some immediate - but negative - effects of openness on product development performance”, Technovation, Vol. 31 No. 1, pp. 54-64.

Kogut, B. and Zander, U. (1992), "Knowledge of the firm, combinative capabilities, and the replication of technology", Organization Science, Vol. 3 No. 3, pp. 383-397.

Kotabe, M., Martin, X. and Domoto, H. (2003), "Gaining from vertical partnerships: knowledge transfer, relationship duration, and supplier performance improvement in the US and Japanese automotive industries", Strategic Management Journal, Vol. 24 No. 4, pp. 293-316.

Kraaijenbrink, J. (2012), "Integrating knowledge and knowledge processes: a critical incident study of product development projects", Journal of Product Innovation Management, Vol. 29 No. 6, pp. 1082-1096.

Kumar, J.A. and Ganesh, L.S. (2011), "Balancing knowledge strategy: codification and personalization during product development”, Journal of Knowledge Management, Vol. 15 No. 1, pp. 118-135.

Lakemond, N., Berggren, C. and van Weele, A. (2006), "Coordinating supplier involvement in product development projects: a differentiated coordination typology", R\&D Management, Vol. 36 No. 1, pp. 55-66.

Lau, A.K.W., Tang, E. and Yam, R.C.M. (2010), "Effects of supplier and customer integration on product innovation and performance: empirical evidence in Hong Kong manufacturers", Journal of Product Innovation Management, Vol. 27 No. 5, pp. 761-777.

Laursen, K. and Salter, A. (2006), "Open for innovation: the role of openness in explaining innovation performance among UK manufacturing firms", Strategic Management Journal, Vol. 27 No. 2, pp. 131-150.

Laursen, K. and Salter, A. (2014), "The paradox of openness: appropriability, external search and collaboration”, Research Policy, Vol. 43 No. 5, pp. 867-878.

Lawson, B., Petersen, K.J., Cousins, P.D. and Handfield, R.B. (2009), "Knowledge sharing in interorganizational product development teams: the effect of formal and informal socialization mechanisms", Journal of Product Innovation Management, Vol. 26 No. 2, pp. 156-172.

Li, Y. and Vanhaverbeke, W. (2009), "The effects of inter-industry and country difference in supplier relationships on pioneering innovations", Technovation, Vol. 29 No. 12, pp. 843-858.

March, J.G. (1991), "Exploration and exploitation in organizational learning", Organization Science, Vol. 2 No. 1, pp. 71-87.

Marsh, S.J. and Stock, G.N. (2006), "Creating dynamic capability: the role of intertemporal integration, knowledge retention, and interpretation", Journal of Product Innovation Management, Vol. 23 No. 5, pp. $422-436$.

Miles, M.B. and Huberman, A.M. (1994), "Qualitative data analysis: an expanded sourcebook", Sage, Thousand Oaks, CA.

Modi, S.B. and Mabert, V.A. (2007), "Supplier development: improving supplier performance through knowledge transfer", Journal of Operations Management, Vol. 25 No. 1, pp. 42-64.

Mu, J. and Di Benedetto, A. (2012), "Networking Capability and New Product Development", IEEE Transactions on Engineering Management, Vol. 59 No. 1, pp. 4-19.

Nonaka, I. (1994), "A dynamic theory of organizational knowledge creation", Organization Science, Vol. 5 No. 1, pp. 14-37.

Okhuysen, G.A. and Eisenhardt, K.M. (2002), "Integrating knowledge in groups: how formal interventions enable flexibility", Organization Science, Vol. 13 No. 4, pp. 370-386. 
Oxley, J.E. and Sampson, R.C. (2004), "The scope and governance of international R\&D alliances", Strategic Management Journal, Vol. 25 Nos 8/9, pp. 723-749.

Parker, H. (2012), "Knowledge acquisition and leakage in inter-firm relationships involving new technology-based firms", Management Decision, Vol. 50 No. 9, pp. 1618-1633.

Prieto, I.M., Revilla, E. and Rodríguez-Prado, B. (2009), "Managing the knowledge paradox in product development", Journal of Knowledge Management, Vol. 13 No. 3, pp. 157-170.

Ranucci, R.A. and Souder, D. (2015), "Facilitating tacit knowledge transfer: routine compatibility, trustworthiness, and integration in M \& As", Journal of Knowledge Management, Vol. 19 No. 2, pp. 257-276.

Remneland-Wikhamn, B. and Knights, D. (2012), "Transaction cost economics and open innovation: implications for theory and practice", Creativity and Innovation Management, Vol. 21 No. 3, pp. 277-289.

Schiele, H. (2006), "How to distinguish innovative suppliers? Identifying innovative suppliers as new task for purchasing", Industrial Marketing Management, Vol. 35 No. 8, pp. 925-935.

Schmickl, K. and Kieser, A. (2008), "How much do specialists have to learn from each other when they jointly develop radical product innovations?", Research Policy, Vol. 37 No. 3, pp. 473-491.

Takeishi, A. (2001), "Bridging inter and intra-firm boundaries: management of supplier involvement in automobile product development", Strategic Management Journal, Vol. 22 No. 5, pp. 403-433.

Tatikonda, M.V. and Rosenthal, S.R. (2000), "Technology novelty, project complexity, and product development project execution success: a deeper look at task uncertainty in product innovation", IEEE Transactions on Engineering Management, Vol. 47 No. 1, pp. 74-87.

Tell, F. (2011), "Knowledge integration and innovation: a survey of the field", in Berggren, C., Bergek, A., Bengtsson, L., Hobday, M. and Söderlund, J. (Eds), Knowledge Integration and Innovation: Critical Challenges Facing International Technology-Based Firms, Oxford University Press, Oxford, pp. 20-58.

Tiwana, A. and McLean, E.R. (2005), "Expertise integration and creativity in information systems development", Journal of Management Information Systems, Vol. 22 No. 1, pp. 13-43.

Un, C.A., Cuervo-Cazurra, A. and Asakawa, K. (2010), "R\&D Collaborations and Product Innovation", Journal of Product Innovation Management, Vol. 27 No. 5, pp. 673-689.

Wagner, B.A. (2003), "Learning and knowledge transfer in partnering: an empirical case study", Journal of Knowledge Management, Vol. 7 No. 2, pp. 97-113.

Williamson, O.E. (1979), "Transaction-cost economics: the governance of contractual relations", Journal of Law and Economics, Vol. 22 No. 2, pp. 233-261.

Williamson, O.E. (2002), "The theory of the firm as governance structure: from choice to contract", The Journal of Economic Perspectives, Vol. 16 No. 3, pp. 171-195.

Yin, R.K. (2009), Case Study Research: Design and Methods, Sage Publications.

Zollo, M. and Winter, S.G. (2002), "Deliberate learning and the evolution of dynamic capabilities", Organization Science, Vol. 13 No. 3, pp. 339-351.

\section{Corresponding author}

Nicolette Lakemond can be contacted at: nicolette.lakemond@liu.se

For instructions on how to order reprints of this article, please visit our website: www.emeraldgrouppublishing.com/licensing/reprints.htm

Or contact us for further details: permissions@emeraldinsight.com 